\title{
Optimalisasi Desain Parameter Lapangan Untuk Data Resistivitas Pseudo 3D
}

\author{
Makhrani* \\ *)Program Studi Geofisika Jurusan Fisika FMIPA Universitas Hasanuddin \\ E-mail : rani_anshar@yahoo.co.id
}

\begin{abstract}
ABSTRAK
Penelitian yang berjudul Optimalisasi Desain Parameter Lapangan Untuk Data Resistivitas Pseudo 3D dilakukan dengan tujuan memprediksi model geologi dan mengestimasi parameter-parameter geofisika, menentukan sensitivitas dari konfigurasi Wenner-Schlumberger dan Wenner dalam mendeteksi anomali, membuat Pseudo 3D dari profil 2D serta meningkatkan kemampuan dalam memilih parameter survei yang optimal berdasarkan perbandingan kekuatan signal yang diharapkan dan kharakteristik dari bising (noise). Proses pengambilan data dilakukan dengan menggunakan metode geolistrik konfigurasi WennerSchlumberger dan konfigurasi Wenner. Pengolahan data geolistrik resistivitas dalam penelitian ini diawali dengan pengolahan data sintetik hasil forward modeling. Data ini dapat dijadikan sebagai data masukan pada perangkat lunak Surfer 9 untuk menggambarkan profil 2D. Seluruh hasil inversi dalam bentuk profil 2D akan digabungkan sehingga menjadi profil pseudo 3D, proses ini akan dilakukan dengan menggunakan perangkat lunak Matlab R2008a. Kedua konfigurasi yang digunakan dalam penelitian ini masing-masing memiliki keunggulan dan kelemahan dalam hal sensitivitas, baik konfigurasi WennerSchlumberger maupun konfigurasi Wenner. Meskipun kedua konfigurasi mendeteksi anomali yang dibuat, namun konfigurasi Wenner-Schlumberger lebih menonjolkan anomali, baik pada data sintetik maupun pada hasil pengukuran. Selain itu, pembuatan pseudo 3D dari profil 2D dapat membantu dalam menginterpretasi data pada lintasan yang saling berpotongan.
\end{abstract}

Kata kunci : optimalisasi desain, data sintetik, pseudo 3D.

\section{PENDAHULUAN}

Metoda geolistrik adalah metoda eksplorasi geofisika yang kompleks karena terdiri dari bermacam-macam metoda, diantaranya metode tahanan jenis (resistivity), metode potensial diri (self potential), metoda potensial terimbas (induced potential) dan lain-lain. Metode geolistrik tahanan jenis memanfaatkan sifat resistivitas listrik batuan untuk mendeteksi dan memetakan kondisi bawah permukaan.

Metode ini dilakukan melalui pengukuran beda potensial yang ditimbulkan akibat injeksi arus listrik ke dalam bumi. Berdasarkan nilai resistivitas listriknya, struktur bawah permukaan bumi dapat diketahui material penyusunnya. Metode geolistrik cukup murah dan sensitif dalam mendeteksi lapisan konduktor sehingga cocok digunakan dalam eksplorasi dangkal (Grandis, 2009).

Dalam metoda geofisika, data pengamatan merupakan respon dari kondisi geologi bawah permukaan. Respon tersebut timbul karena adanya variasi parameter fisika yakni sifat konduktivitas yang merefleksikan formasi/struktur geologi bawah permukaan. Model adalah representasi keadaan geologi oleh besaran fisika agar permasalahan dapat disederhanakan dan responnya dapat diperkirakan atau dihitung secara teoritis.
Besaran atau variabel yang digunakan untuk mengkarakterisasi model disebut parameter model yang secara umum terdiri dari parameter fisika serta variasinya terhadap posisi (Hendrajaya 1990).

Sumber yang berada di dekat permukaan umumnya secara tradisional diperlakukan sebagai bising (noise) dalam survei eksplorasi geofisika yang dalam penyelidikan hidrologi, lingkungan dan geologi teknik sering kali menjadi target. Geologi bawah permukaan biasanya kompleks dan multi skala dengan vatiasi spasial dapat berubah dengan cepat sepanjang profil survei, baik secara lateral maupun vertikal terhadap kedalaman. Oleh karena itu, grid jarak titik pengamatan yang dibuat harus bisa menunjukkan akurasi spasial yang tinggi sehingga target yang diinginkan dapat tercapai. Demikian pula dengan desain survei geolistrik tahanan jenis haruslah memperhitungkan kemampuan dari sistem akuisisi data, heterogenitas dari konduktivitas listrik bawah permukaan dan resolusi yang diinginkan. Faktor-faktor lain yang harus dipertimbangkan adalah areal sejauh mana daerah yang akan diselidiki, biaya survei dan waktu yang dibutuhkan. 
Tujuan dari penelitian ini adalah memprediksi model geologi dan mengestimasi parameter-parameter geofisika, menentukan sensitivitas dari konfigurasi WennerSchlumberger dan Wenner dalam mendeteksi anomali. membuat pseudo 3D dari profil 2D serta meningkatkan kemampuan dalam memilih parameter survei yang optimal berdasarkan perbandingan kekuatan signal yang diharapkan dan kharakteristik dari bising (noise).

\section{LANDASAN TEORI}

\subsection{Pemodelan ke Depan (Forward Modeling)}

Pemodelan ke depan (forward modeling) menyatakan proses perhitungan data yang secara teoritis akan teramati di permukaan bumi (Grandis, 2009).

Apabila diketahui parameter model bawah permukaan tertentu maka melalui proses pemodelan ke depan dapat dihitung data yang secara teoritik akan teramati di permukaan bumi. Konsep tersebut digunakan untuk menginterpretasi/menafsirkan data geofisika. Jika respon suatu model cocok dengan data maka model yang digunakan untuk memperoleh respon tersebut dapat dianggap mewakili kondisi bawah permukaan tempat pengukuran.

\subsection{Pemodelan ke Belakang (Inverse Modeling)}

Menke (1984) dalam Grandis (2009) mendefinisikan teori inversi sebagai suatu kesatuan teknik atau metode matematika dan statistika untuk memperoleh informasi parameter model yang berguna mengenai suatu sistem fisika, dalam hal ini fenomena yang ditinjau berdasarkan observasi terhadap sistem. Dalam proses inversi harus melibatkan proses modifikasi model agar diperoleh kesesuaian optimal antara data perhitungan dan pengamatan. Pemodelan jenis ini juga dinamakan data fitting karena dalam prosesnya dicari parameter model yang menghasilkan respons yang sesuai dengan data pengamatan.

Kesesuaian antara respons model dengan data pengamatan umumnya dinyatakan dalam suatu fungsi objektif yang harus diminimumkan. Proses pencarian minimum fungsi objektif tersebut berasosiasi dengan proses pencarian model optimum.

\subsection{Sifat Kelistrikan Batuan}

Batuan mempunyai sifat-sifat kelistrikan karena batuan merupakan suatu jenis materi. Sifat kelistrikan batuan adalah karakteristik dari batuan bila dialirkan arus listrik ke dalamnya.
Dalam hal ini akan dikaji tentang potensial listrik alam dari batuan, konduktivitas batuan dan konstanta dielektrik batuan.

Potensial listrik batuan adalah potensial listrik alam atau potensial diri disebabkan terjadinya kegiatan elektrokimia atau kegiatan alam. Faktor pengontrol dari semua kejadian ini adalah air tanah. Potensial alam ini dapat dikelompokkan menjadi 4 kelompok, yaitu :

1. Potensial Elektrokinetik. Potensial ini disebabkan bila suatu larutan bergerak melalui pipa kapiler atau medium yang berpori.

2. Potensial Diffusi. Potensial ini terjadi bila terdapat perbedaan mobilitas dari ion dalam larutan yang mempunyai konsentrasi berbeda.

3. Potensial Nerust. Potensial ini timbul bila suatu elektroda dimasukkan ke dalam larutan homogen.

4. Potensial Mineralisasi. Potensial ini timbul bila dua elektroda logam dimasukkan ke dalam larutan homogen. Potensial ini paling besar bila dibandingkan dengan jenis potensial lainnya. Biasanya potensial ini timbul pada zona yang mengandung banyak sulfida, grafit dan magnetik.

Sedangkan penyebab jenis potensial alam lainnya, seperti korosi, bioelektrik, gradien temperatur dan gradien tekanan sudah tercakup dalam salah satu dari kelompok di atas (Hendrajaya, 1990).

Pada bagian batuan, atom-atom terikat secara ionik atau kovalen. Karena adanya ikatan ini maka batuan mempunyai sifat menghantarkan arus listrik. Aliran arus listrik dalam batuan/mineral dapat digolongkan menjadi tiga macam yaitu :

1. Konduksi Elektronik. Konduksi ini adalah tipe normal dari aliran arus listrik dalam batuan/mineral.

2. Konduksi Elektrolitik. Konduksi jenis ini banyak terjadi pada batuan atau mineral yang bersifat porus dan pori-porinya tersebut terisi oleh larutan elektrolit.

3. Konduksi Dielektrik. Konduksi ini terjadi pada batuan yang lebih bersifat dielektrik.

Konduktivitas batuan berpori bervariasi tergantung pada volume, susunan pori dan kandungan air di dalamnya. Sementara itu konduktivitas air sendiri bervariasi yaitu tergantung pada banyaknya ion yang terdapat di dalamnya (Hendrajaya, 1990). 


\subsection{Konsep Dasar Geolistrik}

Penggunaan geolistrik pertama kali dilakukan oleh Conrad Wenner-Schlumberger pada tahun 1912. Konsep dasar dari Metoda Geolistrik adalah Hukum Ohm yang pertama kali dicetuskan oleh George Simon Ohm. Formulasi dari hukum Ohm dapat dituliskan sebagai berikut:

$$
V=I \cdot R
$$

Metoda geolistrik tahanan jenis merupakan metoda yang bersifat aktif dengan mengalirkan arus listrik ke dalam lapisan bumi melalui dua elektroda arus, sedangkan potensialnya diukur melalui dua buah elektroda potensial atau lebih.

Pada pengukuran geolistrik tahanan jenis, biasanya digunakan dua buah elektroda arus $\mathrm{C}$ di permukaan. Besarnya potensial pada titik P di permukaan akan dipengaruhi oleh kedua elektroda tersebut (Gambar 1).

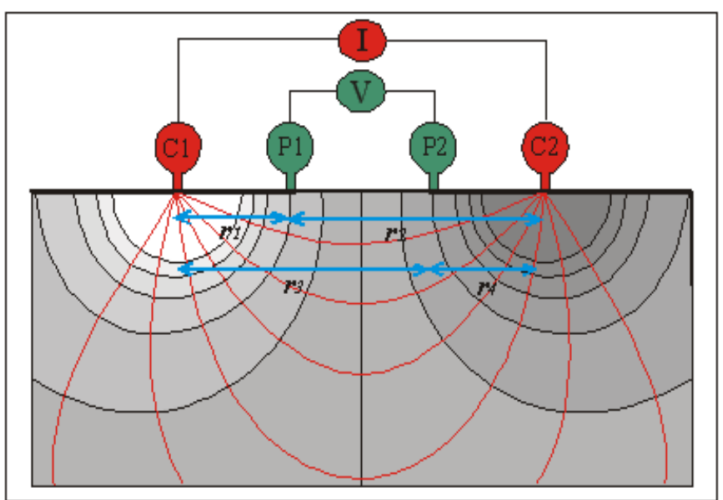

Gambar 1 Potensial pada Dua Elektroda Arus (Loke \& Barker, 1996)

Potensial pada titik $\mathrm{P}_{1}$ dan $\mathrm{P}_{2}$ yang disebabkan oleh arus dari elektroda $\mathrm{C}_{1}$ dan $\mathrm{C}_{2}$ akan diuraikan dalam metode penelitian.

Berdasarkan susunan penempatan elektroda pengukuran terdapat berbagai jenis konfigurasi pengukuran diantaranya konfigurasi Wenner Alpha, Wenner Beta, Wenner Gamma, Pole-Pole, Dipole-Dipole, Pole-Dipole, WennerWenner Schlumberger, dan Equatorial DipoleDipole. Masing-masing konfigurasi ini memiliki karakterisitik tersendiri, sehingga setiap konfigurasi memiliki kelebihan dan kekurangan. Gambar 2 menunjukkan berbagai bentuk susunan (konfigurasi) elektroda. Setiap konfigurasi tersebut menghasilkan faktor geometri yang berbeda-beda di mana faktor geometri ini akan digunakan dalam perhitungan hasil pengukuran. Konfigurasi pengukuran yang relatif banyak digunakan dalam keperluan praktis di antaranya konfigurasi WennerSchlumberger, Wenner, Wenner-Wenner Schlumberger dan dipol-dipol.

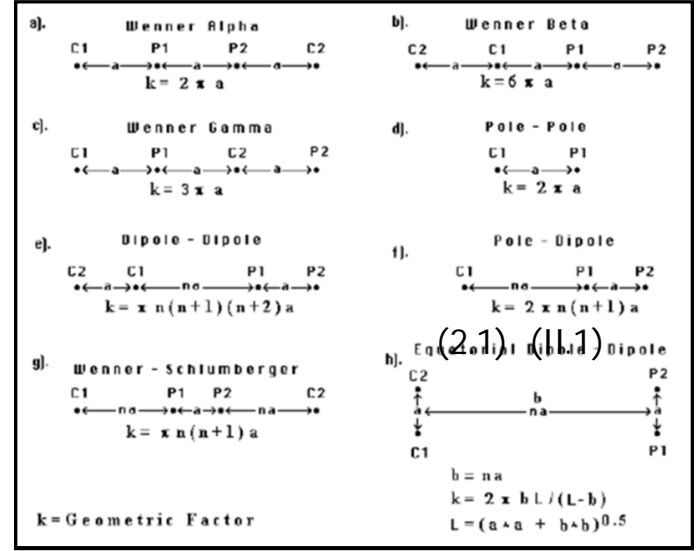

Gambar 2 Konfigurasi elektroda dalam eksplorasi geolistrik (Loke, 2004)

\section{METODE PENELITIAN}

Hal yang paling penting sebelum pengambilan data dilakukan adalah pembuatan rancangan penelitian berupa model geologi (data sintetik). Dari model geologi sintetik tersebut kemudian dilakukan pemodelan ke depan untuk melihat respon resistivitasnya dalam mendeteksi anomali yang dibuat. Tujuan dari pemodelan ke depan ini adalah untuk mendapatkan desain parameter lapangan, terutama jarak elektroda yang digunakan dalam pengambilan data di lapangan.

Alat geolistrik yang digunakan dalam penelitian ini adalah satu unit Resistivitimeter hambatan jenis S-Field dan beberapa peralatan pendukung lainnya.

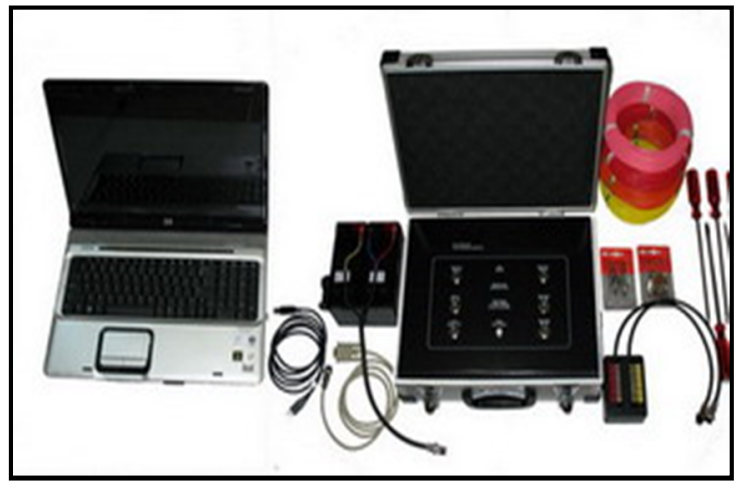

Gambar 3 Alat geolistrik tahanan jenis S-Field

Pengambilan data dilakukan secara langsung di lapangan dengan menggunakan konfigurasi Wenner dan konfigurasi Wenner-Schlumberger. Berdasarkan Gambar 1 di atas, potensial pada titik $\mathrm{P}_{1}$ yang disebabkan oleh arus dari elektroda $\mathrm{C}_{1}$ dan $\mathrm{C}_{2}$ adalah:

$$
V(r)=\frac{I \rho}{2 \pi r} \text { atau } \rho=2 \pi r \frac{V}{I}
$$


Beda potensial di titik $\mathrm{P}_{1}$ akibat arus $\mathrm{C}_{1}$ dan $\mathrm{C}_{2}$ menjadi:

$\mathrm{V}_{1}+\mathrm{V}_{2}=\frac{I \rho}{2 \pi}\left(\frac{1}{r_{1}}-\frac{1}{r_{2}}\right)$

Demikian pula potensial yang timbul pada titik $\mathrm{P}_{2}$ akibat arus dari elektorda $\mathrm{C}_{1}$ dan $\mathrm{C}_{2}$, sehingga beda potensial antara titik $\mathrm{P}_{1}$ dan $\mathrm{P}_{2}$ ditulis sebagai

$\Delta V=\frac{I \rho}{2 \pi}\left[\left(\frac{1}{r_{1}}-\frac{1}{r_{2}}\right)-\left(\frac{1}{r_{3}}-\frac{1}{r_{4}}\right)\right]=\frac{I \rho}{k}(4)$

atau

$k=\frac{2 \pi}{\left(\frac{1}{r_{1}}-\frac{1}{r_{2}}\right)-\left(\frac{1}{r_{3}}-\frac{1}{r_{4}}\right)}$

Sehingga

$\rho=k \frac{\Delta V}{I}$

dimana $\mathrm{k}$ adalah faktor geometri yang bergantung pada susunan elektroda

Pengolahan data geolistrik tahanan jenis dalam penelitian ini diawali dengan pengolahan data sintetik hasil forward modeling. Data ini diperoleh dari model sintetik yang dibuat dengan menggunakan perangkat lunak Res2Dmod yang menghasilkan penampang apparent resistivity, yang kemudian diinversikan dengan menggunakan perangkat lunak Res2Dinv yang mengasilkan profil 2D true resistivity. Parameter pada model sintetik ini kemudian dijadikan parameter lapangan untuk akuisisi data.

Hasil inversi dengan menggunakan perangkat lunak Res2Dinv berupa profil 2D secara vertikal yang dapat menunjukkan kedalaman dan sebaran resistivitas sebenarnya. Keluaran Res2Dinv dari hasil inversi juga dapat berupa angka/nilai dalam bentuk data koordinat $(\mathrm{x}, \mathrm{y}, \mathrm{z})$. Data yang dimaksud terdiri atas data spasial dan nilai resistivitas sebenarnya (true resistivity). Data ini dijadikan sebagai data masukan pada perangkat lunak Surfer 9 untuk menggambarkan profil 2D. Seluruh hasil inversi dalam bentuk profil 2D akan digabungkan sehingga menjadi profil pseudo 3D, proses ini akan dilakukan dengan menggunakan perngkat lunak Matlab R2008a.

Untuk keperluan interpretasi, hasil resistivitas berupa penampang $2 \mathrm{D}$ digunakan untuk melihat anomali yang ada. Tentunya akan dibandingkan dengan penampang resistivitas 2D sebelum ada anomalinya. Seluruh penampang resistivitas yang ada kemudian digabungkan untuk menghasilkan profil resistivitas pseudo 3D untuk melihat distribusi anomali secara spasial.

\section{HASIL DAN PEMBAHASAN \\ 4.1 Model Geologi}

Model ini dibuat di lokasi penelitian dengan dua buah drum yang menjadi anomali berupa drum kosong dan drum berisi air, ditanam pada kedalaman 1 meter dari permukan tanah dan jarak antara kedua drum adalah 3 meter.

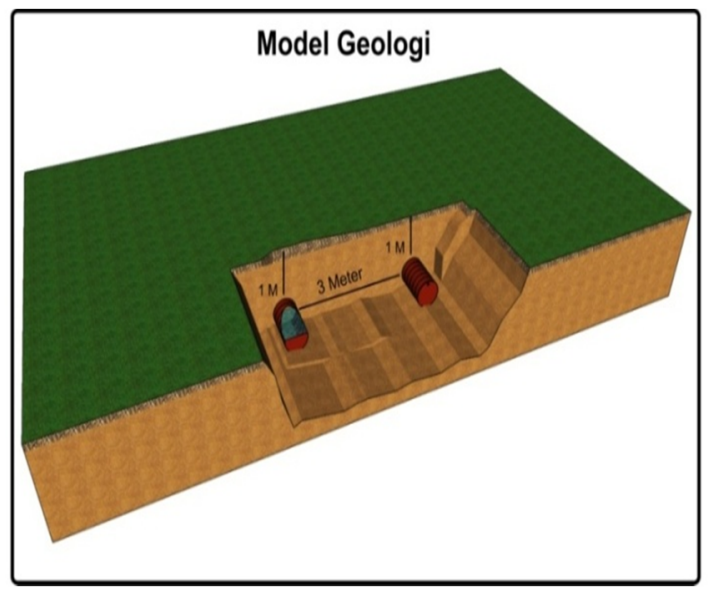

Gambar 4 Model geologi dengan 2 buah drum

Sebelum model ini dibuat, terlebih dahulu dilakukan pengukuran dengan posisi lintasan memotong masing-masing drum maupun memotong kedua drum sehingga ada 3 lintasan yang di akuisisi (Gambar 5)

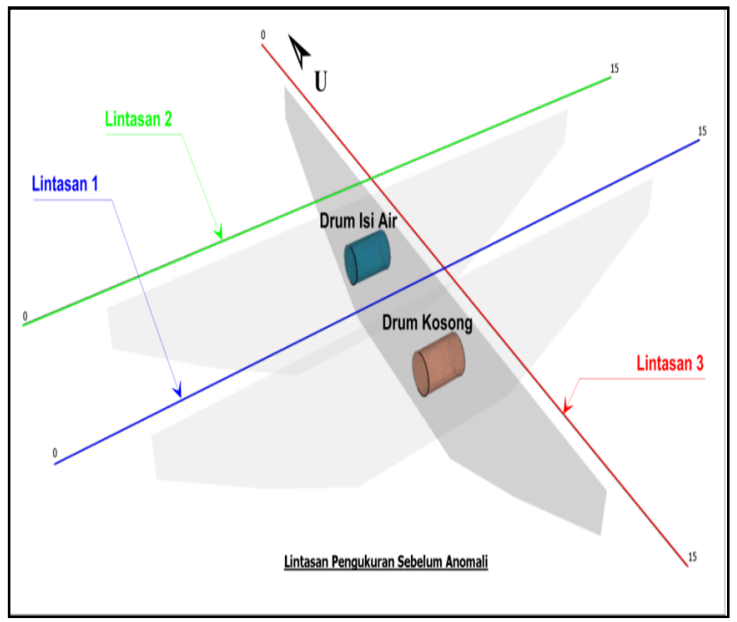

Gambar 5 Lintasan pengukuran resisitivitas sebelum anomali ditanam

\subsection{Model Sintetik}

Sebelum dilakukan pengukuran di lapangan, maka terlebih dahulu dibuat data sintetik yang disesuaikan dengan model geologi. Hal ini dilakukan untuk penyederhanaan model geologi dan penentuan desain parameter yang 
akan dilakukan sebenarnya pada model geologi. Untuk drum kosong diasumsikan memiliki resistivitas $50 \Omega \mathrm{m}$, drum berisi air resistivitasnya $30 \Omega \mathrm{m}$ dan resistivitas latar belakangnya (background) diberi nilai resistivitas $100 \Omega \mathrm{m}$.

Model sintetik konfigurasi Wenner Schlumberger dibuat menggunakan metode forward modeling (pemodelan kedepan) dengan software RES2mod. Untuk itu dibuat model setiap lintasan yang sudah ditentukan. Gambar 6 berikut adalah salah satu model hasil overlay data sintetik spasi 0,5 meter dan 1 meter.

Pada Gambar 6, terlihat bahwa lintasan diambil memotong 2 anomali drum yang berisi air dan yang kosong, sehingga dibuat data sintetik dengan spasi 0,5 meter yang memotong masingmasing blok model, sehingga hasil overlay dari data sintetik menghasilkan pembacaan anomali yang tepat.

Selain dari konfigurasi WennerSchlumberger juga dibuat model dengan konfigurasi Wenner menggunakan blok model yang sama. Hasil inversi konfigurasi Wenner pada lintasan 3 Utara-Selatan yang memotong dua buah blok model anomali menunjukan bahwa anomali yang terdeteksi hanya pada blok model dengan nilai resistivitas $30 \Omega \mathrm{m}$, sedangkan untuk blok model dengan nilai resistivitas $50 \Omega \mathrm{m}$ dapat dilihat melalui nilai resistivitas hasil inversi yang melebar dengan nilai resistivitas sekitar 92-95 $\Omega \mathrm{m}$, seperti diperlihatkan pada Gambar 7.

\subsection{Pengukuran Resistivitas Model Geologi Sebelum dan SetelahAdanya Anomali}

Hasil parameter lapangan dari model sintetik yang dibuat kemudian dijadikan dasar untuk memilih jarak elektroda yang digunakan yaitu 0,5 dan 1 meter. Hal ini karena dari model sintetik tersebut dapat diidentifikasi anomali yang dibuat. Pengukuran sebelum anomali dimaksudkan untuk melihat keadaan awal sebelum ada anomali yang kemudian akan dijadikan referensi untuk pengukuran saat anomali sudah ada di bawah permukaan tanah.

Pengukuran setelah anomali adalah pengukuran yang dilakukan secara keseluruhan dengan jumlah lintasan sebanyak 12 lintasan meliputi 5 lintasan arah Utara-Selatan dan 7 lintasan arah Timur-Barat. Tiga lintasan arah Utara-Selatan yaitu lintasan dua, tiga dan empat memotong dua anomali drum kosong maupun drum yang berisikan air serta dua lintasan lainya yaitu lintasan satu dan lima berada di luar anomali, untuk lintasan arah Timur-Barat, lintasan yang berada di luar anomali yaitu lintasan satu, empat, dan tujuh. Lintasan dua dan tiga memotong anomali drum kosong serta lintasan lima dan enam memotong anomali drum berisikan air, (Gambar 8). Untuk akuisisi data lapangan setiap lintasan dilakukan tiga kali pengambilan data. Hal ini penting dilakukan dengan tujuan menghindari kualitas data yang buruk.

Di bawah ini dapat dilihat gambar lintasan pengukuran sesudah anomali, profil 2D WennerSchlumberger sebelum anomali dan sesudah anomali.

\subsection{PSEUDO 3D}

Hasil dari seluruh penampang 2D, baik menggunakan konfigurasi Wenner dan konfigurasi Wenner-Schlumberger kemudian dibuat profil pseudo 3D untuk masing-masing konfigurasi.

Dari hasil pengukuran dengan konfigurasi Wenner-Schlumberger, baik pada model geologi maupun pada data sintetik dibuat pseudo 3D dari profil 2D. Gambar 11 menunjukan hasil inversi data sintetik dan hasil inversi dari data pengukuran. Hasil inversi overlay pada data sentetik menunjukan bahwa anomali dideteksi dengan baik pada posisi yang tepat, baik secara vertikal maupun horizontal, sama halnya pada hasil inversi overlay data pengukuran. Hasil overlay pada data pengukuran memperlihatkan adanya pola yang menyerupai anomali, ditunjukkan pada point A dan B, namun pola ini juga terbentuk pada hasil overlay dari data sintetik. Yang membedakan keduanya hanyalah nilai resistivitas.

Untuk konfigurasi Wenner (Gambar 12) memperlihatkan pseudo 3D dari data sintetik dan data hasil pengukuran. Pada model sintetik, hasil inversinya menunjukan kedua anomali dapat dideteksi dengan nilai resistivitas 87 - 91 $\Omega \mathrm{m}$ tidak seperti konfigurasi WennerSchlumberger yang mendeteksi anomali dengan pola lingkaran yang lebih kecil. Pada konfigurasi Wenner mendeteksi anomali dengan pola lingkaran yang lebih melebar, bahkan pada lintasan tiga arah Utara-Selatan yang melintasi kedua buah drum memperlihatkan anomali yang terlihat menyatu. Hasil inversi pada data pengukuran memperlihatkan bahwa anomali drum tidak terdeteksi dalam bentuk pola lingkaran, tetapi melebar dengan nilai resistivitas yang redah antara $30-70 \Omega \mathrm{m}$. Pola ini menyatu pada bagian bawah karena resapan air yang juga mempunyai nilai resistivitas yang rendah, sama seperti drum.

Berikut adalah gambar dari pseudo 3D untuk konfigurasi Wenner-Schlumberger dan konfigurasi Wenner. 


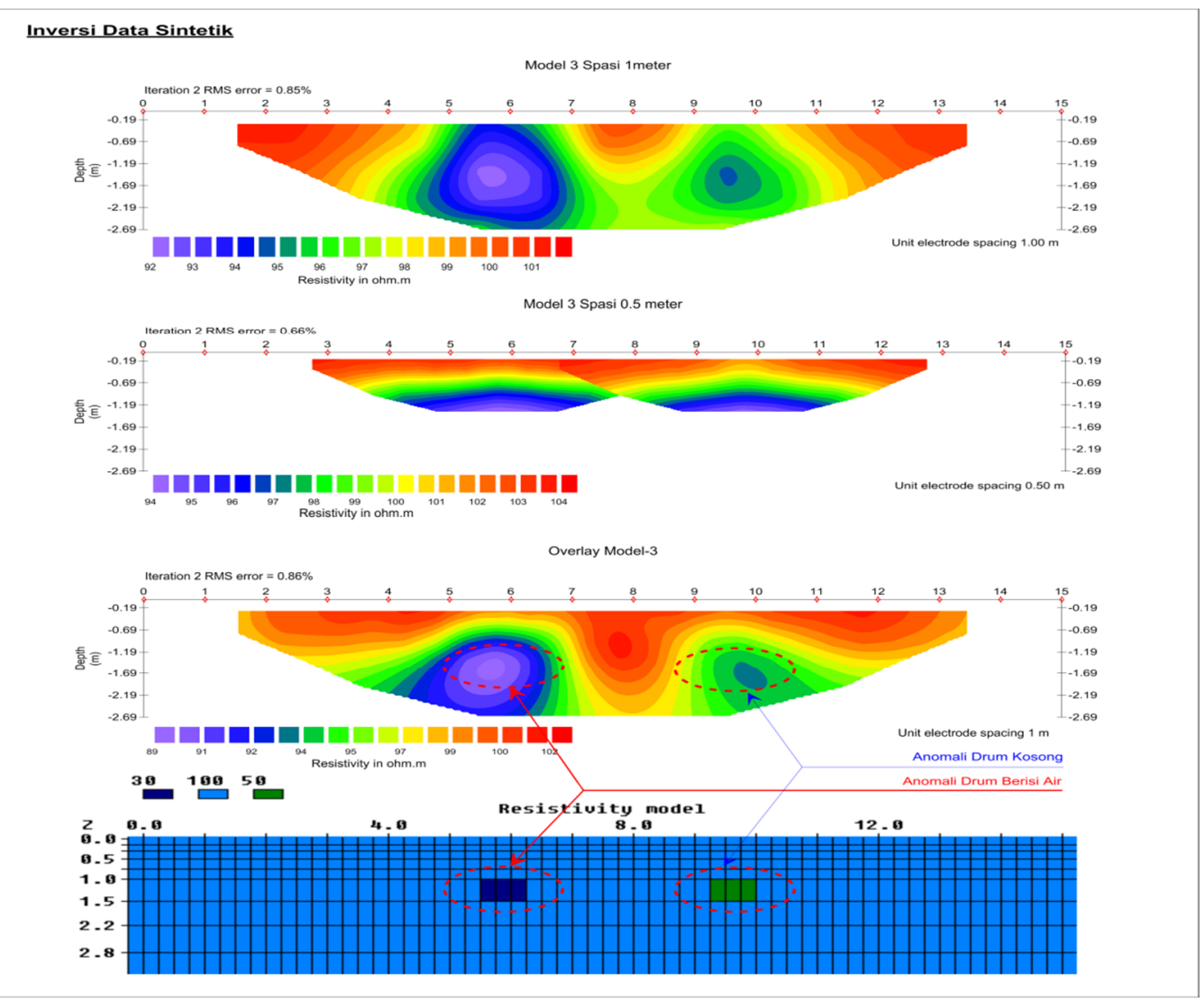

Gambar 6. Overlay data sintetik spasi 0,5 dan 1 meter

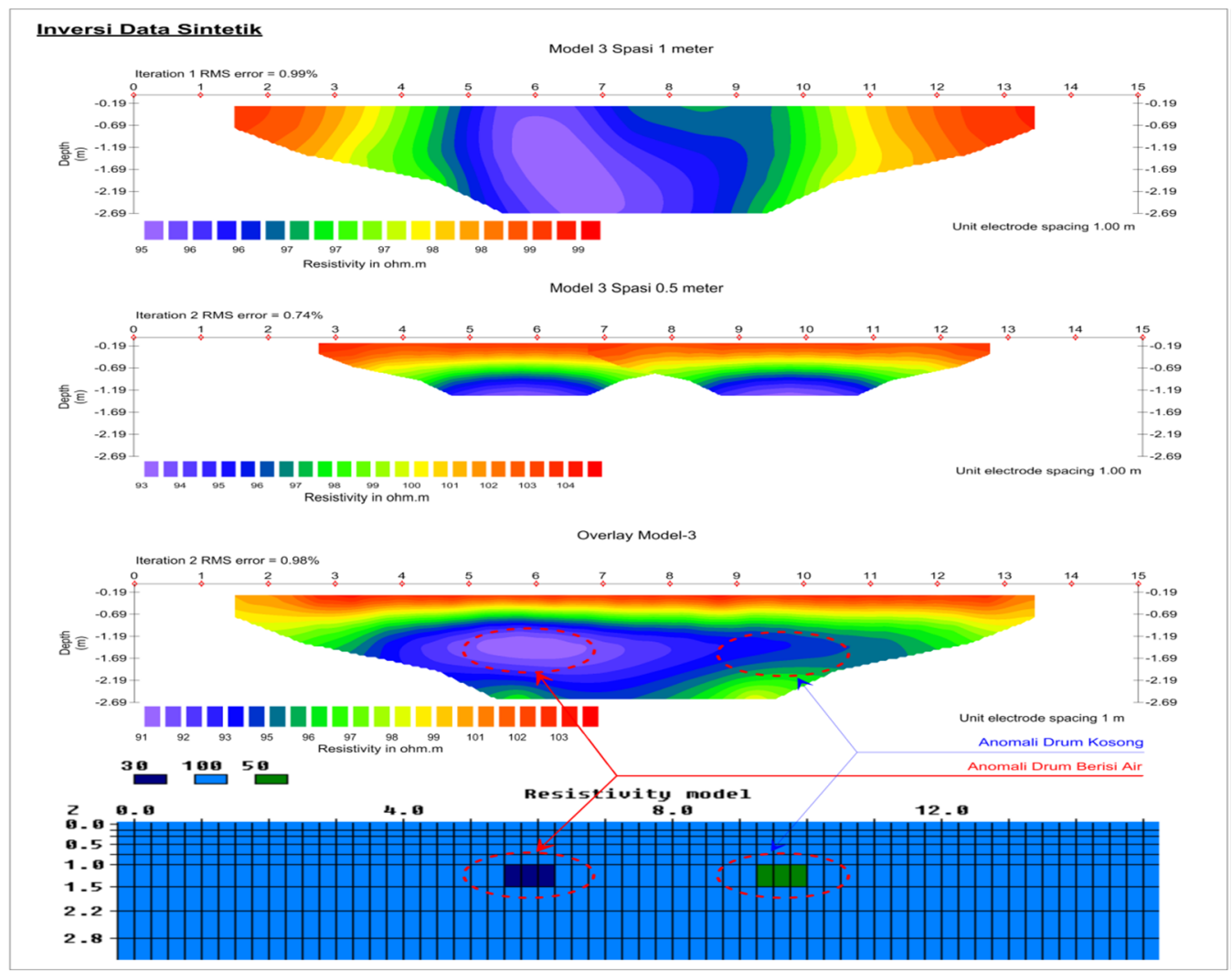

Gambar 7. Overlay data sintetik spasi 0,5 dan 1 meter 


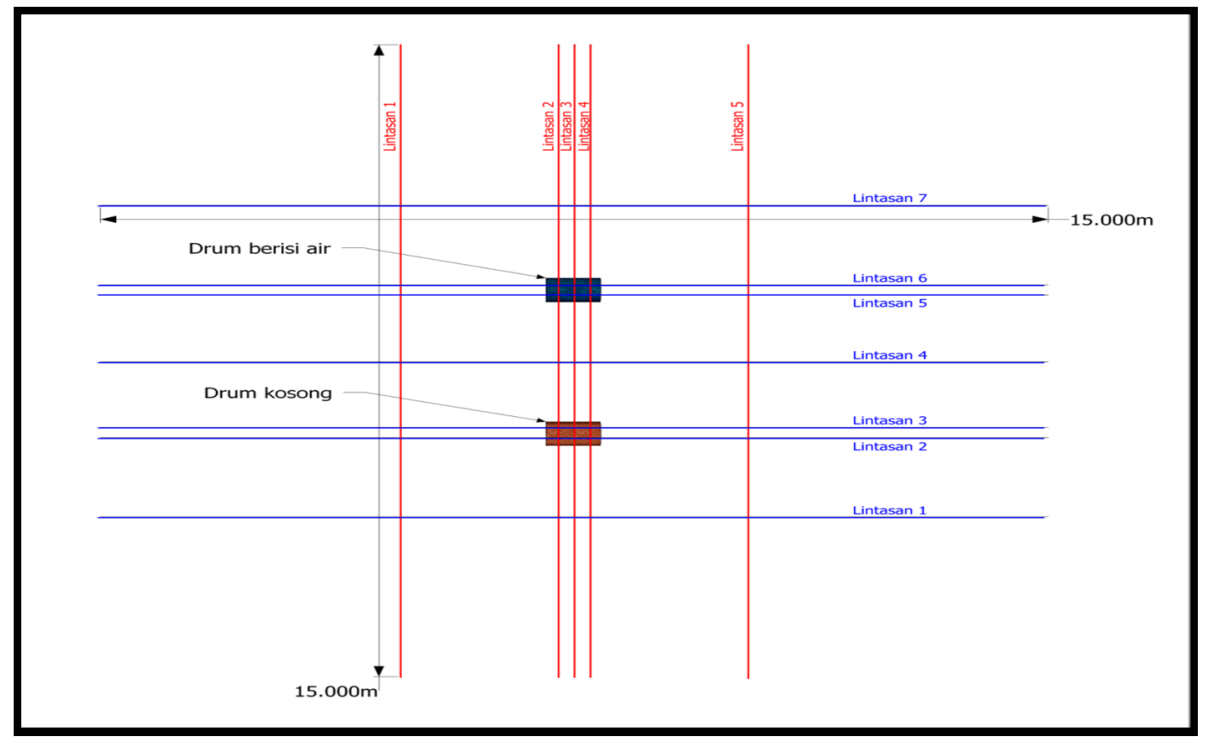

Gambar 8. Lintasan pengukuran sesudah anomali

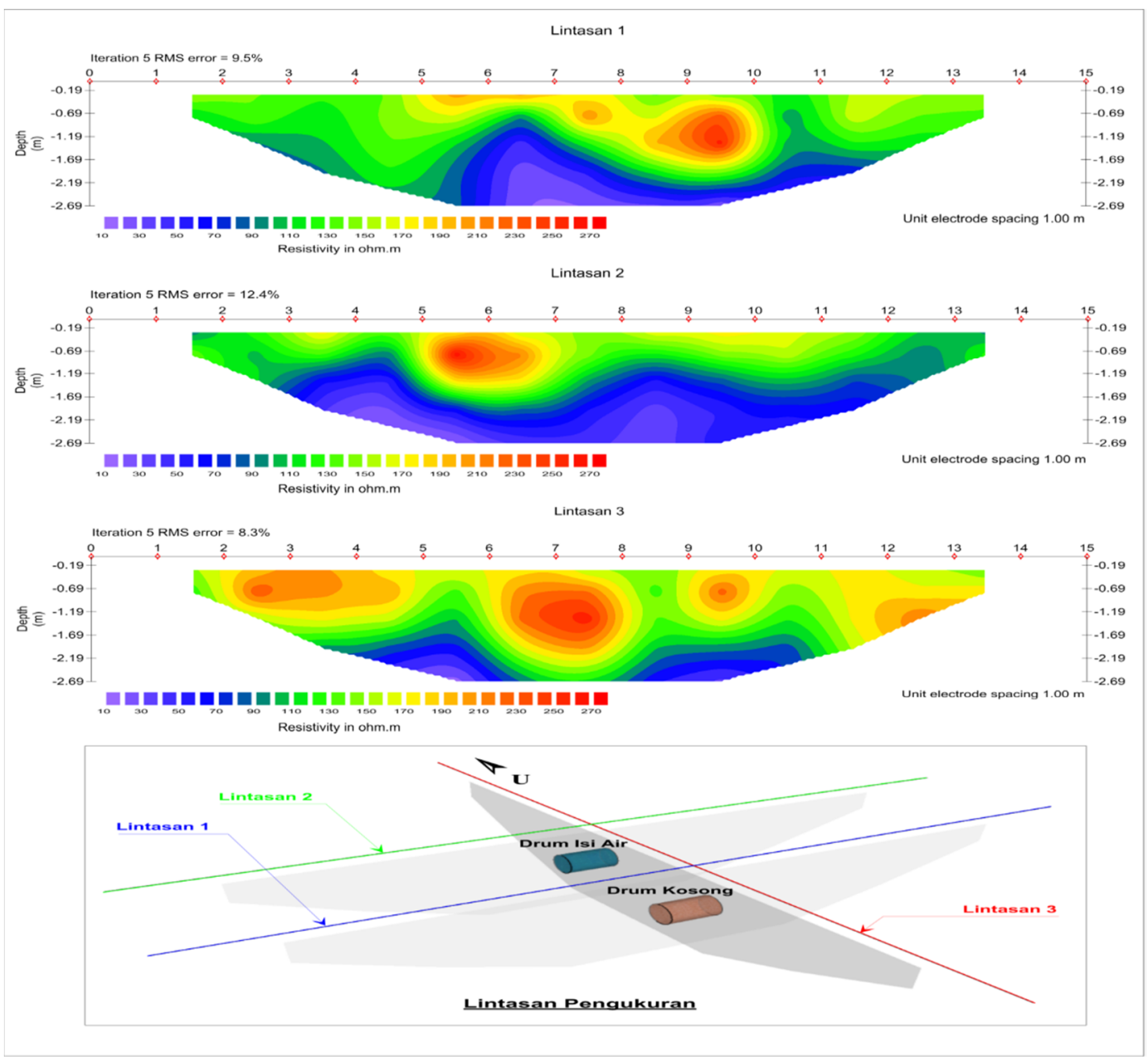

Gambar 9. Profil 2D Wenner-Schlumberger sebelum anomali 


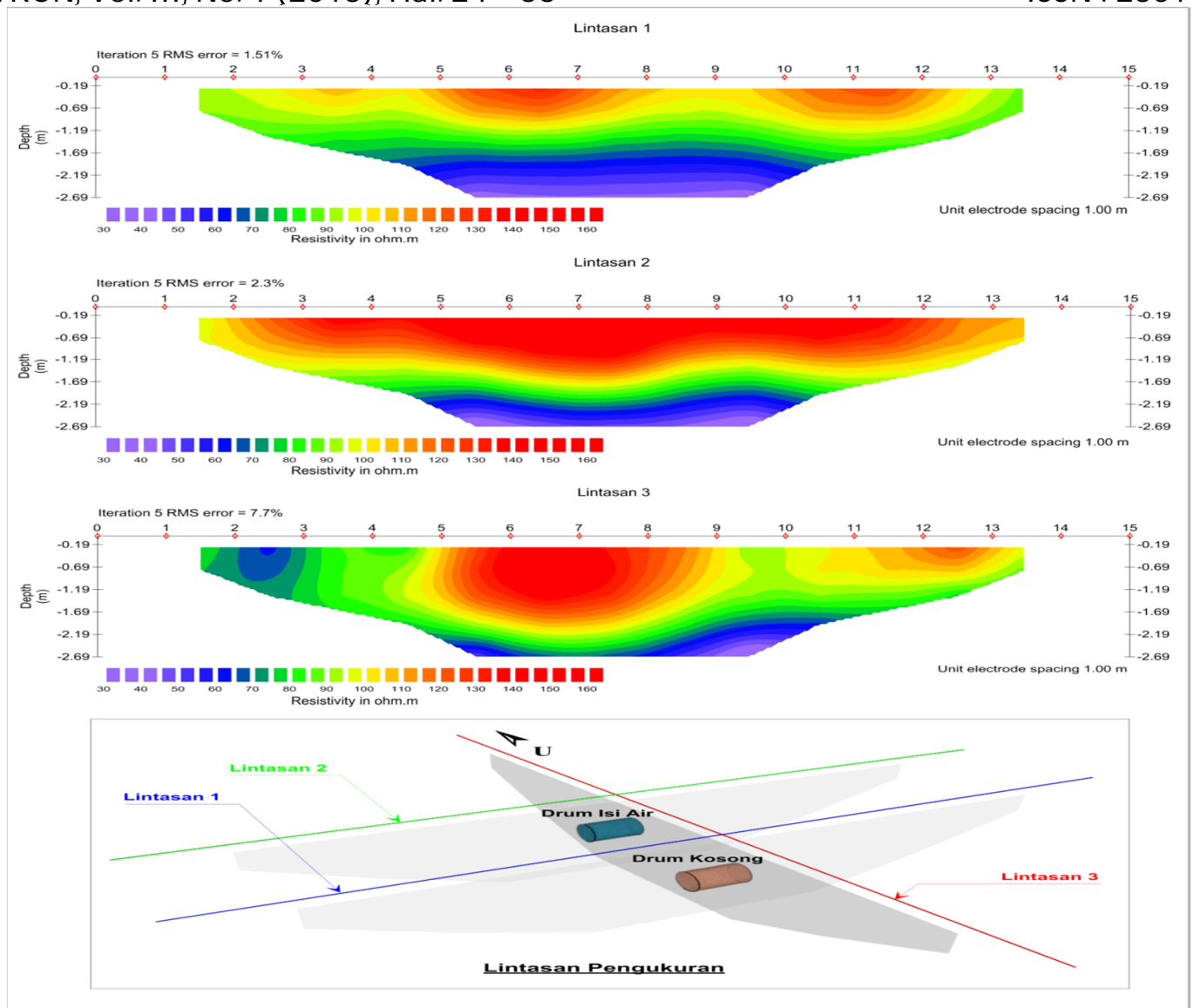

Gambar 10 Profil 2D Wenner sebelum anomali

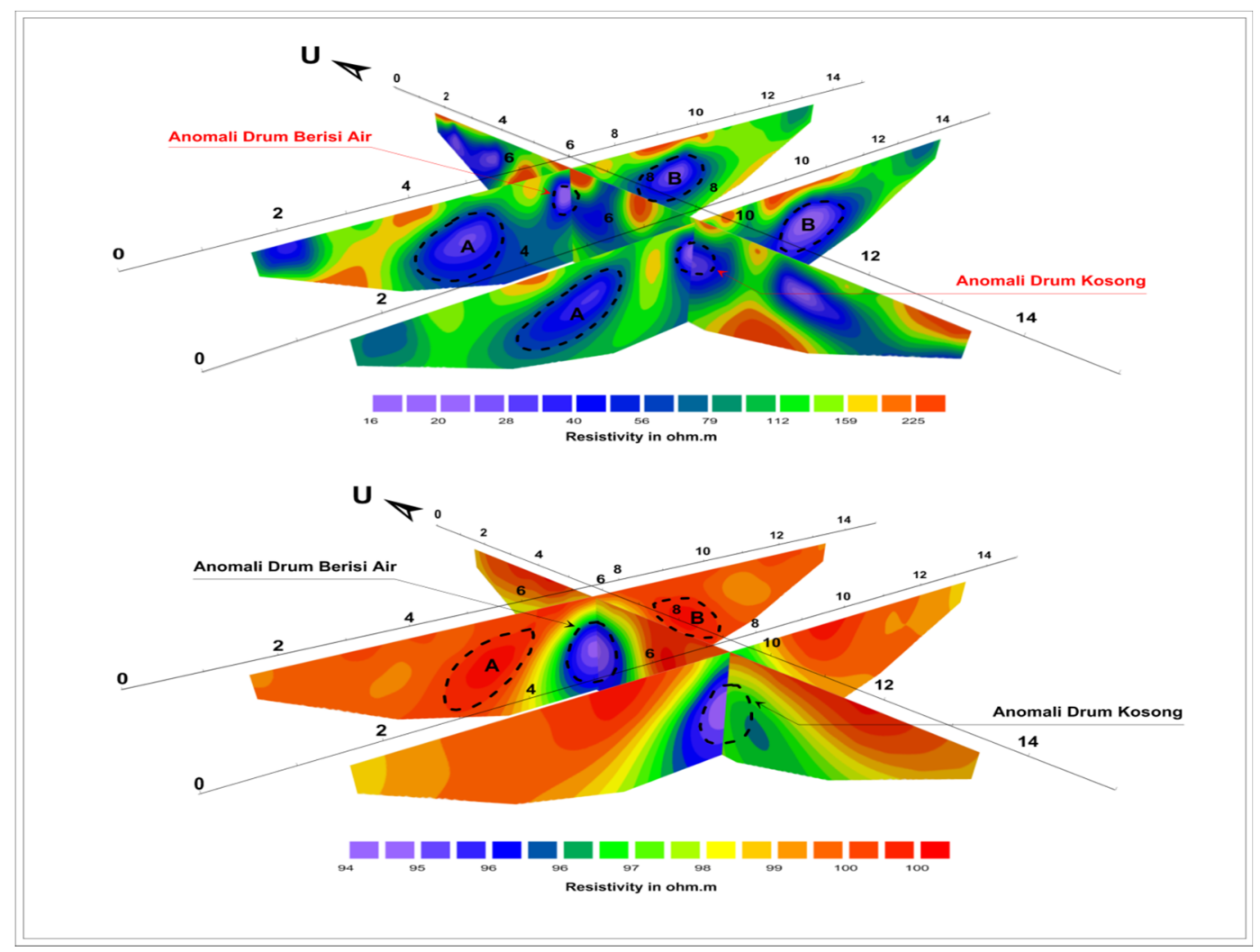

Gambar 11 Pseudo 3D Konfigurasi Wenner-Schlumberger 


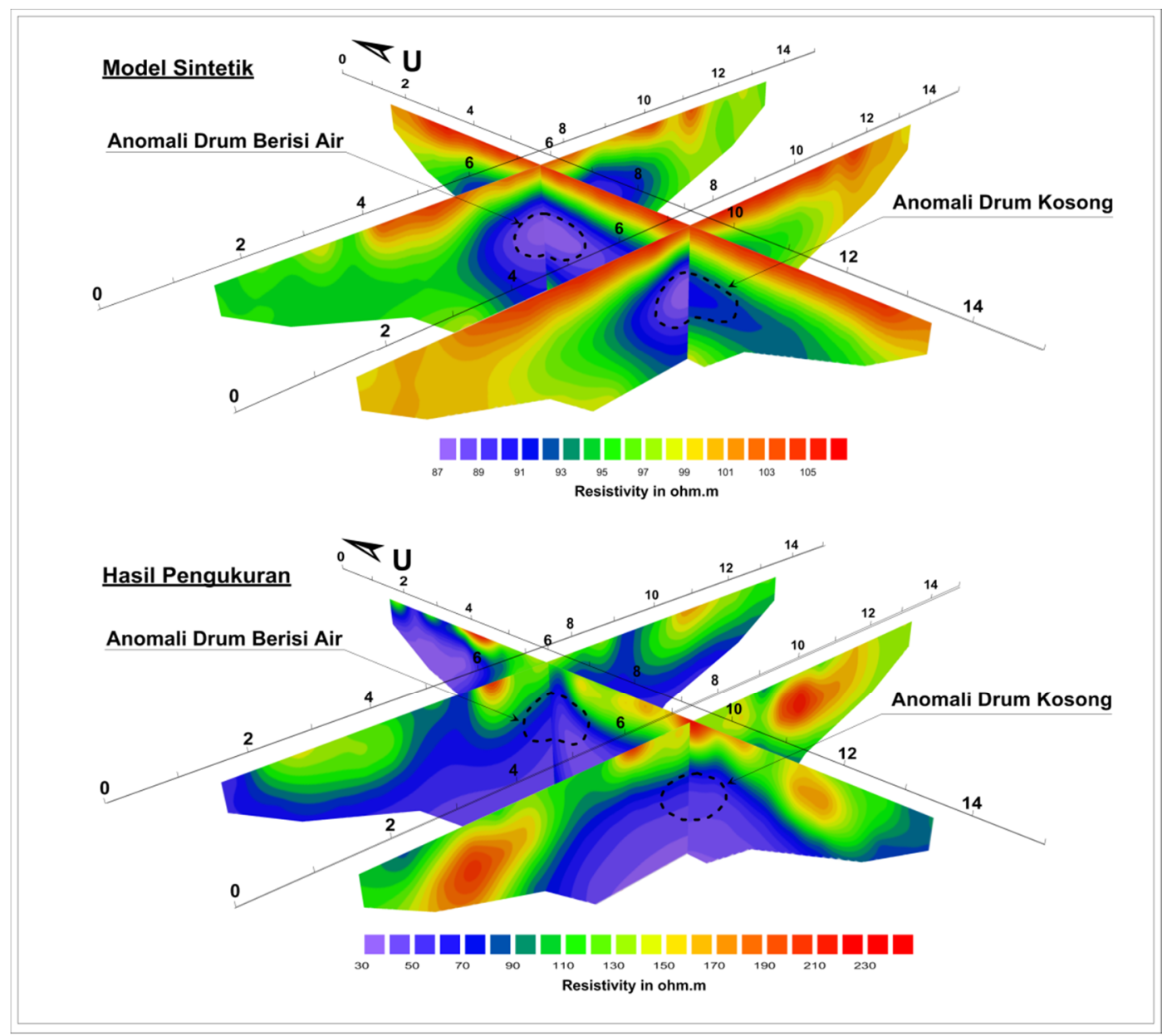

Gambar 12 Pseudo 3D Konfigurasi Wenner

\section{KESIMPULAN}

Dari hasil yang diperoleh di atas dapat disimpulkan beberapa hal sebagai berikut:

1. Dari kedua konfigurasi yang digunakan dalam penelitian ini masing-masing memiliki keunggulan dan kelemahan. Dalam hal sensitivitas baik konfigurasi WennerSchlumberger maupun Wenner mendeteksi anomali yang dibuat, namun konfigurasi Wenner-Schlumberger lebih menonjolkan anomali, baik pada data sintetik maupun pada hasil pengukuran.

2. Pemilihan spasi elektroda memiliki peranan penting dalam mendeteksi anomali yang diinginkan.

3. Pembuatan pseudo 3D dari profil 2D dapat membantu interpretasi pada lintasan yang saling memotong.

4. Dari hasil inversi data sintetik dan data hasil pengukuran baik pada konfigurasi WennerSchlumberger maupun Wenner memiliki perbedaan karena pada data sintetik hasil forward modeling bersifat homogen isotropis, berbeda dengan model geologi yang memiliki sifat heterogen anisotropis.

5. Pembuatan pseudo 3D dari profil 2D dapat membantu interpretasi pada lintasan yang saling memotong.

6. Dari hasil inversi data sintetik dan data hasil pengukuran baik pada konfigurasi WennerSchlumberger maupun Wenner memiliki perbedaan karena pada data sintetik hasil forward modeling bersifat homogen isotropis, berbeda dengan model geologi yang memiliki sifat heterogen anisotropis.

\section{DAFTAR PUSTAKA}

1. Grandis, H., 2009, Pengantar pemodelan inverse geofisika, Himpunan Ahli Geofisika Indonesia 
2. Hendrajaya, L ., 1990, Metode Geolistrik Tahanan Jenis, ITB, Bandung.

3. Loke M.H. and Barker R.D., 1996, Rapid Least-square Inversion of Apparent Resistivity Pseudosections using a Quasinewton Method, Geophysical Prospecting, 44 .

4. Loke, M. H., 2004, Geoelectrical Imaging 2D \& 3D,RES2DINV ver 3.3:Rapid 2D Resistivities \& IP Inversion using the least-square method On Land, Underwater and Cross-borehole surveys, Penang, Malaysia.

5. Olhoeft, G.R., 1981, Electrical Properties of Rocks : In Physical Properties of Rocks and Minerals, New York, McGraw-Hill

6. Taib, M.I.T., 2004., Eksplorasi Geolistrik, Diktat Kuliah Metoda Geolistrik, Departemen Teknik Geofisika, ITB, Bandung.

7. Telford, W.M., L.P. and Sheriff, R.P. (1990), Applied Geophysics second edition, Cambridge University Press 